\title{
Determination of climatological seasons for the East Coast of the U.S. using an air mass-based classification
}

\author{
Shouquan Cheng ${ }^{1}$, Laurence S. Kalkstein ${ }^{2, *}$ \\ ${ }^{1}$ Department of Geography, The Chinese University of Hong Kong, Shatin, New Territories, Hong Kong \\ ${ }^{2}$ Center for Climatic Research, Department of Geography, University of Delaware, Newark, Delaware 19716, USA
}

\begin{abstract}
This paper discusses the application of a year-round synoptic classification procedure to define climatological seasons based upon the frequency occurrence of seasonal air masses. The classification is developed through air mass 'seed day' identification and discriminant function analysis, and assigns each day to 1 of 18 air mass types for each of 14 stations along the East Coast of the United States. Unlike the 'astronomical' definition of seasons, which divides a year into 4 equal periods, the length of winter ranges from about $1 \frac{1}{2}$ mo in Miami, Florida to more than 4 mo in Portland, Maine as determined by air mass frequencies. The summer extends more than 5 mo in Florida, while it only lasts 3 mo in Maine. In the mid-Atlantic region, there are 2 longer seasons (summer and winter; about 4 mo each) and 2 shorter seasons (spring and fall; about 2 mo each). The seasonal definition proposed here more closely corresponds to phenological responses than do traditional definitions. The information can be applied to numerous environmental assessment problems, including animal demographics and habitat distributions, plant phenology and subsequent pollen release, migration and hibernation patterns, human health and psychological responses to climate, and agricultural planning activities.
\end{abstract}

KEY WORDS: Climatological seasons - Synoptic climatology · Spatial synoptic classification · Air masses Discriminant function analysis

\section{INTRODUCTION}

The traditional definition of 'astronomical' seasons divides a year into 4 equal periods, of which summer and winter begin at the appropriate solstice and end with the equinox, and spring and autumn are the days between the equinox and the solstice. Like the astronomical seasons, the 'meteorological' definition of seasons often divides a year into four 3 mo periods, with Northern Hemisphere winter defined as December-February, spring as March-May, summer as June-August, and autumn as September-November. Unfortunately, these definitions are arbitrary and independent of the actual climatology and physical geography of the region. In reality, the length of the seasons varies systematically and consistently across a

\footnotetext{
·E-mail: larryk@udel.edu
}

climatological gradient, such as the East Coast of the U.S. From Florida to Maine, the length of summer should decrease, and the length of winter should increase, as reflected in a variety of phenomena such as biological activity, phenology of plants, extent of snow cover, and even human activity. This, of course, is also true at mid-latitude locations around the world.

Arbitrary definitions of seasons are not useful for understanding variability in these and other seasonally-dependent events, such as faunal demographics and migrations, utility consumption, and planting scheduling. Although most biota do respond to regional and interannual changes in seasonal patterns, human activity is much less responsive; consider the start and end of 'swimming season', which is often from late May to early September in many mid-latitude Northern Hemisphere locations. In addition, the procedure here may be applied to a variety of environmental problems which seem less obviously connected to sea- 
sonality These include studies to understand regional climate variation through evaluation of frequencies and meteorological characteristics of seasonal air masses (Kalkstein et al. 1996), studies relating to seasonal variation of air quality (Kalkstein \& Corrigan 1986, Cheng et al. 1992) and precipitation (McCabe 1985, Greene 1995), evaluation of the year-round impact of climate on human health (Kalkstein 1991a, Cheng 1991), and assistance to utility companies and other seasonally-based industries which alter protocol based on the annual cycle of weather. If climatological seasons can be specifically defined for different locales, it would be easier to comprehend how organisms respond to climatic variability, and the possibility of altering human behavior and activity to the actual timing of seasons could be facilitated.

In this research, a climatological season is defined as an interval of time within a yearly cycle with definitive air mass attributes. These may be described in terms of distinctive seasonal air mass frequencies and climatological properties. Of course, alterations in these air mass characteristics are affected by atmospheric circulation patterns (Schwartz \& Marotz 1986, 1988), which are somewhat seasonal in themselves. However, most organisms and activities on the earth's surface respond directly to air mass characteristics rather than to circulation patterns, and if these air mass attributes can be defined in some quantitative manner throughout the year, seasonal length can be determined for a multitude of locales.

Much of the previous research on seasonal delineation has used atmospheric circulation patterns (Lie \& Wu 1956, Yeh \& Chu 1958, Brádka 1966, Kalnicky 1987 ) or key individual weather variables (Zhang 1934, Gordon 1953, Bryson \& Lahey 1958, Matsumoto 1990, Green 1993), although a few air mass-based studies have also been attempted (Lamb 1950, Pielke et al. 1987. Schwartz \& Marotz 1988). The use of upper level atmospheric circulation to divide seasons is best applied to a large spatial scale (such as seasonal differentiation between the tropical zone and the temperate zone), but is difficult to utilize when evaluating seasonal differences between places a few hundred kilometers apart (e.g. Philadelphia and Boston). The use of individual weather variables poses a different dilemma, as organisms respond to the entire suite of meteorological elements which comprise an air mass, rather than to arbitrarily-selected meteorological variables (Kalkstein 1991b, McMichael et al. 1996). To overcome this shortcoming, Lamb (1950) and Pielke et al. (1987) utilized frequencies of weather types and air masses to define seasons for the British Isles and several locations in the United States, respectively. However, their techniques were based on manual evaluation of daily surface weather maps, which can be exceedingly time-consuming and data-intensive when treating a climatological period of many years for a number of locations

The objective of this study is to define the climatological seasons over the east coast of the United States on the basis of air mass frequencies. An automated year-round spatial synoptic classification (SSC), which is modified from the spatial synoptic classification procedure developed by Kalkstein et al. (1996), is employed to develop a daily calendar of various air masses. This procedure can identify daily air masses over a long period of time in a rather consistent manner for numerous locations. This can be accomplished in a relatively short period of time, rendering the procedure suitable to evaluate a number of locales across an environmental gradient.

\section{METHODOLOGY}

Fourteen National Weather Service first-order stations along the East Coast are evaluated (Fig. 1), with selection based on latitudinal spacing and data completeness. Each station contains at least $43 \mathrm{yr}$ of hourly data, which we deemed as the minimum requirement for classification purposes (Kalkstein et al. 1996).

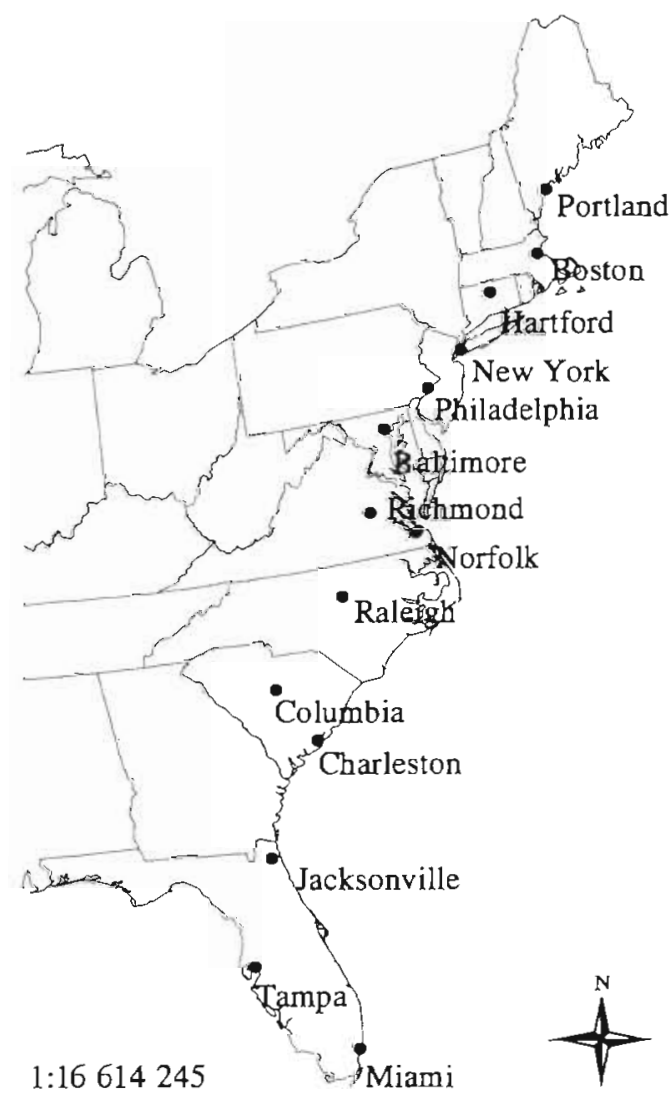

Fig. 1. Location map of study points 
The SSC procedure requires identification of a predetermined set of air mass groups. All days within a sample can be placed within one of these air mass categories. In the procedure, it is initially necessary to distinguish the typical meteorological characteristics of these predetermined air masses.

\subsection{Air mass identification}

Six primary air masses across the eastern U.S. are identified based upon historical observations and weather maps, and an air mass nomenclature has been devised based on the character, rather than the source region, of these air masses (for a more detailed discussion on air mass selection, see Kalkstein et al. 1996). The 4 categories most frequently delineated as air masses ( $\mathrm{mT}, \mathrm{mP}, \mathrm{cT}$, and $\mathrm{cP}$ ) are too restrictive, and ignore the presence of important modifications that take place at mid-latitudes. These include the adiabatic warming and drying of Pacific maritime air masses as they descend the lee side of the Rocky Mountains, and the frequent, persistent presence of 'overrunning' conditions which occur for hundreds of kilometers north of a stationary or warm front. The 6 determined air mass types thus include

(1) dry polar (DP)

(2) dry temperate (DM)

(3) dry tropical (DT)

(4) moist polar (MP)

(5) moist temperate (MM)

(6) moist tropical (MT).

Dry polar is the coldest and occasionally the driest air mass in a region, particularly in winter. It is commonly associated with minimal cloud cover and northerly winds. Dry tropical is characterized by very hot, dry air, little or no cloud cover, and southwesterly winds, and typically originates in the U.S. Desert Southwest or northern Mexico. It is most often associated with the hottest and driest conditions in a region. Dry temperate is typically an adiabatically-warmed Pacific air mass, and is associated with dry, mild conditions in the eastern United States. Moist polar is the cool and moist air mass frequently associated with overcast conditions and easterly winds. Moist tropical, usually originating in the Gulf of Mexico or the tropical oceans, represents warm, humid conditions and southerly winds. This air mass is frequently associated with the warm sector of an open wave cyclone or the western flank of a subtropical anticyclone. Moist temperate is associated with frontal activity to the south ('overrunning') as well as overcast and humid conditions. Its temperature and dew point are much higher than moist polar, but lower than moist tropical.
As the characteristics of these 6 air masses vary considerably among seasons, the SSC used here classifies all days into a set of 18 air mass types, 6 for summer and winter respectively, and 6 for spring and autumn.

\subsection{Selection of seed day criteria}

The procedure used here requires selection of 'seed days' to represent typical air mass situations at each locale. These days represent the typical meteorological character of each air mass at a location, and are used as prototypes to classify all other days into the different air masses.

The seed days for each air mass are selected by evaluating ranges of afternoon temperature, dew point, wind direction, total cloud cover $10=$ clear, $10=$ over cast), dew point depression, and diurnal temperature. Afternoon observations are used because characteristics of air masses are most distinctive during this time, particularly for surface temperature and dew point depression (Kalkstein et al. 1996). In addition, 6-hourly dew point changes are also used for selection of seed days to prevent air mass 'transition days' from being selected as seeds. Estimates of criteria for seed days are specified for each air mass at an initial site through careful evaluation of surface meteorological data and maps. In this study, Philadelphia was selected as the initial site because this mid-latitude location has a distinct 4-season year and is centrally located in the study region. Seed day selection criteria were developed for Philadelphia; these represent the range of conditions acceptable for a day to be selected as an air mass seed (Table 1). All conditions listed must be met for a day to be considered acceptable. The criteria can be iteratively adjusted if the researcher feels the seed days are non-representative. For example, for selecting a member to the Philadelphia summer DT seed day pool, a day must possess an afternoon air temperature of at least $35^{\circ} \mathrm{C}$ (trajectory analysis indicates that DT air masses possess maximum temperatures of at least $35^{\circ} \mathrm{C}$, an afternoon dew point below $14.4^{\circ} \mathrm{C}$, an afternoon cloud cover of less than five-tenths, a diurnal temperature range of at least $5.6^{\circ} \mathrm{C}$ with no maximum limitation, a dew point depression of at least $19^{\circ} \mathrm{C}$, and a southwest to west wind. Sometimes a day not within a particular season might meet the criteria for a seed day within a season (a particularly warm spring day might meet summer MT criteria). Seeds are only selected from that sample of days within a particular period, such as December 15 through February 15 for winter, March 15 to May 15 and September 15 to November 15 for spring and autumn, and June 15 through August 15 for summer. There is a sufficient pool of seed days during these periods to avoid select- 


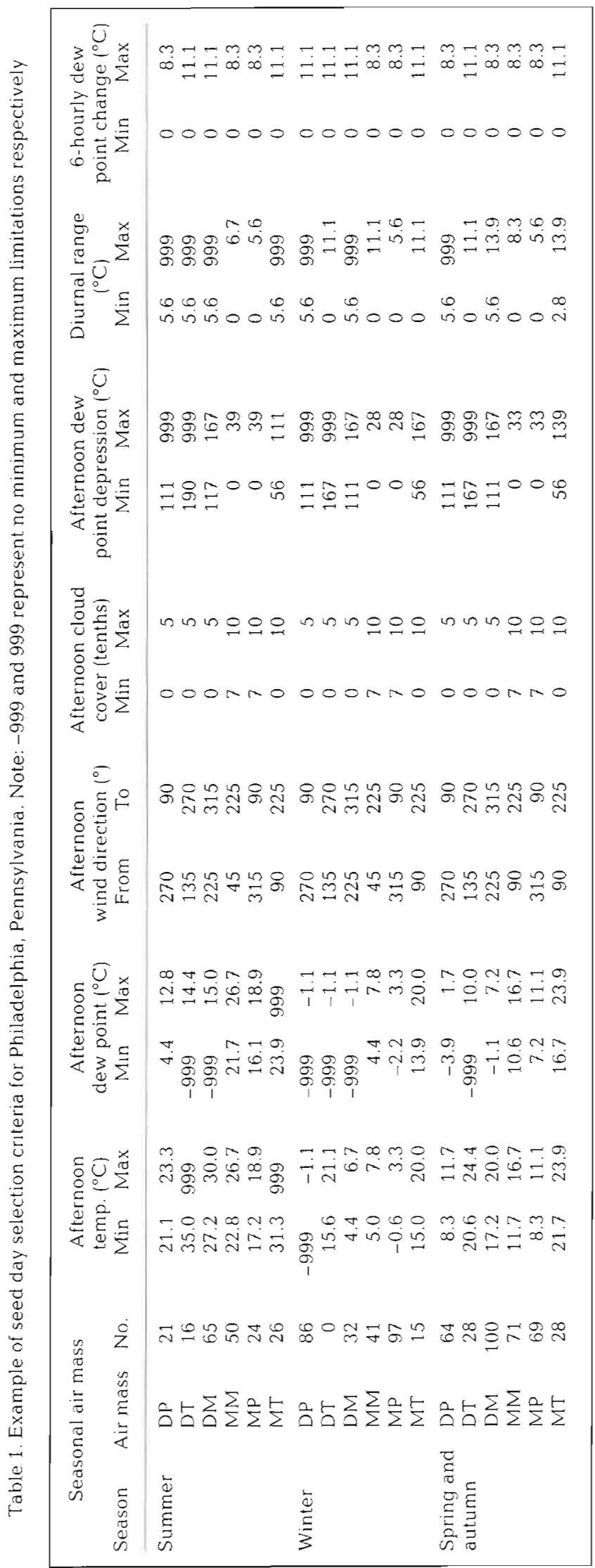

ing days outside of the period. However, previous research has shown that the final result is little affected by the selection of seed days as long as the days are typical for each air mass (Kalkstein et al. 1996).

Following seed day selection for Philadelphia, the seed day selection criteria for adjacent stations (such as New York City or Baltimore) are determined based on comparisons of mean monthly afternoon temperature and dew point temperature in January, July, and April/October between the 2 sites for winter, summer and spring/fall respectively. For example, in Baltimore, if the monthly mean afternoon temperature is $1^{\circ} \mathrm{C}$ higher in January than in Philadelphia, this value is added to the winter seed day selection criteria used for Philadelphia to obtain criteria for Baltimore. Often, the same seed days are thus selected for adjacent locations. Seed days are selected for the 14 stations in this study using a similar adjacent station comparison procedure. After selection, seed days are manually screened for each site to make certain that no meteorologically anomalous days have been included. If possible, at least 15 seed days are selected for each seasonal air mass.

Following seed day selection, discriminant function analysis is used to produce a linear function for each air mass from its group of seed days (refer to Kalkstein et al. 1996 for a justification for using discriminant function analysis). The following 12 variables are used in the discriminant function procedure: 6-hourly temperature and dew point, mean daily cloud cover and sea-level pressure, and diurnal air temperature and dew point ranges. Kalkstein et al. (1996) utilized several combinations of meteorological elements to determine which would be most effective distinguishing between air masses; the 12-variable combination was deemed most effective. Each day is subsequently evaluated using all air mass discriminant functions to determine which group it most closely resembles, resulting in a daily air mass calendar.

Some days are initially incorrectly classified because they represent transition situations. To account for this, a second discriminant function analysis is performed with transition seed days to determine whether or not a day represents a transition situation. The transition seed days are selected similarly to the air mass seed days; however, the selection elements differ. Two particularly meteorologically conservative elements, diurnal dew point and sea level pressure change, are evaluated for selecting transition seed days. If a significant diurnal change is observed for either element (at least twice the average diurnal change for all days), the day is selected as a transition seed day.

Although seed day selection criteria were determined to select seeds for 18 different air masses, only 17 air mass types were found, as no days met the cri- 
teria for DT in winter over the entire study region. Further, not all stations evaluated possess these 17 types. For example, north of Philadelphia, there exists no winter MT air mass during the study period (this is corroborated in Kalkstein et al. 1996). South of Columbia and south of Jacksonville there are no cases of summer DT and summer DP air masses respectively (corroborated in Cheng 1996).

\subsection{Definition of climatological seasons}

The SSC procedure provides a daily air mass calendar for each location. Using this calendar, the frequencies of the 6 air masses in each season are calculated. Five-day running percent frequencies and a cubic spline smoothing procedure are used for each season's air masses to determine the length of each season and to remove extraneous short-term variations. Table 2 is an example of calculating 5-day running percent frequencies. From Day 1 to Day 5, there are 4 winter air mass days and 1 spring-autumn air mass day, which produce the frequencies of $0 \%, 80 \%$, and $20 \%$ for summer, winter, and spring-autumn, respectively. These values are exhibited for the middle day of the 5 consecutive days (Day 3 ) because the mean values represent the condition for the middle of the period.

Two rule changes are necessary to account for air mass transition days (about $12 \%$ of total days). The more frequent case occurs when the transition is between 2 different air masses of the same season (e.g. Day 6 in Table 2); about $70 \%$ of the transition days are of this type. In this case, we assume that the air mass on that transition day still belongs to that particular seasonal category (for Day 6, it is springautumnj. Thus, this transition day is treated exactly like a spring-autumn air mass day. In the less frequent case, the transition is from an air mass that exists in one

Table 2. Hypothetical example of 5-day running percent frequencies

\begin{tabular}{|llrlr|}
\hline Date & Air mass & $\begin{array}{r}\text { 5-day running frequency percentage } \\
\text { Summer } \\
\text { Winter }\end{array}$ & $\begin{array}{r}\text { Spring- } \\
\text { autumn }\end{array}$ \\
& & & & \\
\hline Day 1 & winter DP & & & \\
Day 2 & winter DM & 0 & 80 & 20 \\
Day 3 & winter MM & 0 & 60 & 40 \\
Day 4 & winter MT & 0 & 40 & 60 \\
Day 5 & spring-autumn MM & 0 & 20 & 80 \\
Day 6 & transition day & 0 & 0 & 100 \\
Day 7 & spring-autumn MT & 0 & 0 & 100 \\
Day 8 & spring-autumn DM & 0 & 0 & 75 \\
Day 9 & spring-autumn MM & 25 & & \\
Day 10 & transition day & & & \\
Day 11 & summer MP & & & \\
& & &
\end{tabular}

season to an air mass that exists in a different season (e.g. Day 10 in Table 2). When this occurs, the transition day is omitted from the percent frequency calculation. For example, on Day 10, air masses change from the spring-autumn MM to the summer MP. Thus, for Day 9 (which comprises the running frequency of Days 7 to 11 ), the frequencies are based on 4 days excluding Day 10, and are thus 25\%,0\%, and $75 \%$ for summer, winter, and spring-autumn, respectively.

Seasonal air mass 5-day running frequencies are calculated for every day during the entire period of record (more than 43 yr at each station). Daily mean percent frequencies are computed (the total of 5-day running percent frequencies for a day, such as January 1 , is divided by the number of years evaluated) and are smoothed by the cubic spline smoothing procedure; then they are used to divide the climatological seasons.

\section{RESULTS AND DISCUSSION}

\subsection{Length of seasons}

The frequencies of the seasonal air masses vary systematically across the study sites (Fig. 2a-d). If frequencies of summer air masses exceed $50 \%$ (i.e. summer air masses occur more than 2.5 days within the 5-consecutive-day period), the combination of winter and spring-autumn air masses should be less than $50 \%$. Therefore, the period when summer air mass frequencies are above $50 \%$ is defined as the summer season. Similarly, the period when winter air mass frequencies exceed $50 \%$ is defined as the winter season. The periods between the summer and winter seasons are designated spring and autumn. For example, in Philadelphia (Fig. 2b), the first days of spring, summer, autumn, and winter are March 17, May 25, September 19 , and November 29 , respectively.

This evaluation of climatological seasons for the East Coast suggests that spring begins in Florida almost 2 mo earlier than in Maine (from early February to late March). The latitudinal gradient of the date is about $2.9 \mathrm{~d}$ per $100 \mathrm{~km}$ (Fig. 3). South of Baltimore, the first day of spring changes rapidly with latitude $(3.5 \mathrm{~d}$ per $100 \mathrm{~km})$; however, north of Baltimore, the change appears more gradual (1.4 d per $100 \mathrm{~km}$ ). However, this may be a spurious result, as the stations are distributed more latitudinally south of Baltimore, and more longitudinally to the north (Fig. 1). Nevertheless, there is little change in date for the beginning of spring from New York City northward, suggesting that spring air masses do not extend this far north to any great extent until late March.

The first day of summer varies from early May in Florida to mid-June in Maine (2.0 d per $100 \mathrm{~km}$ ). In the 
(a) Portland, ME: 1949-1991

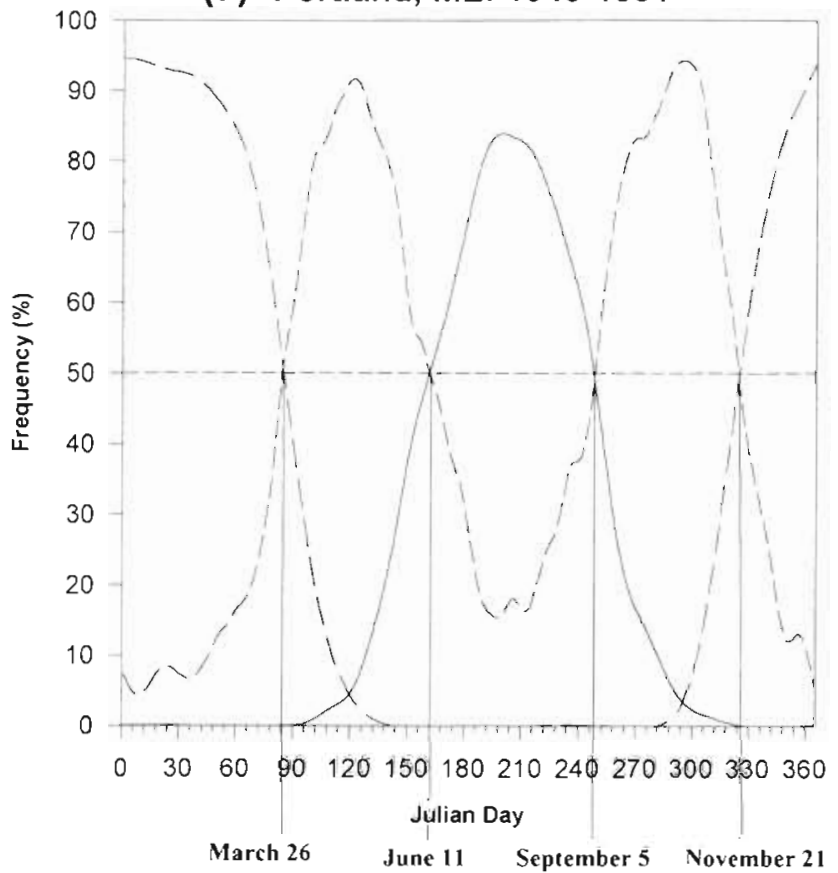

(c) Norfolk, VA: 1948-1991

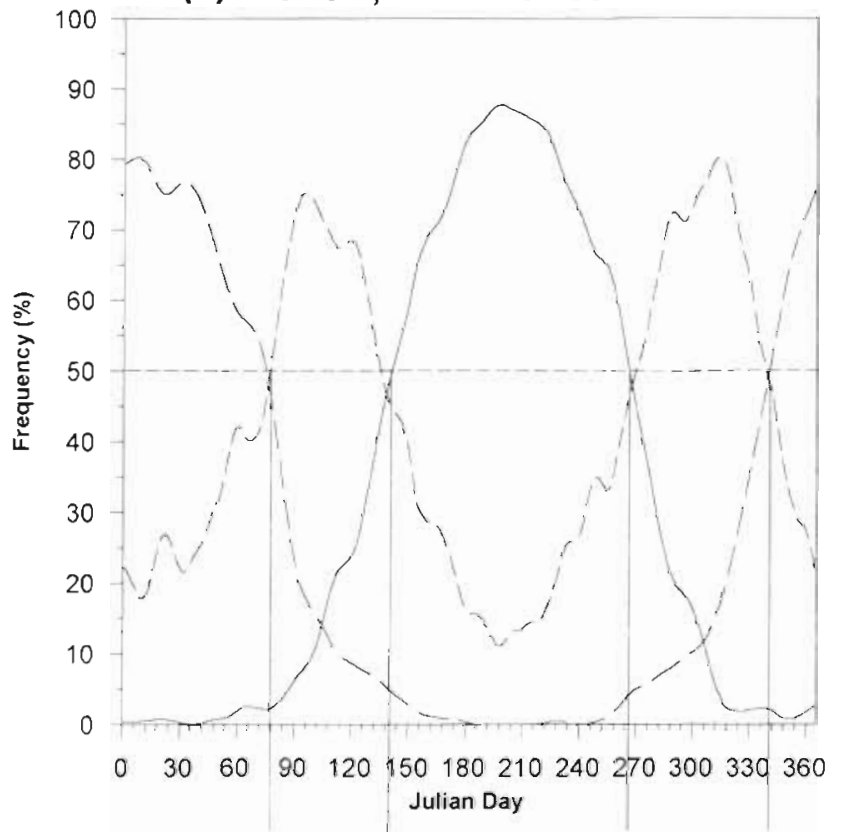

March $17 \quad$ Nay 22

September 24

December 7

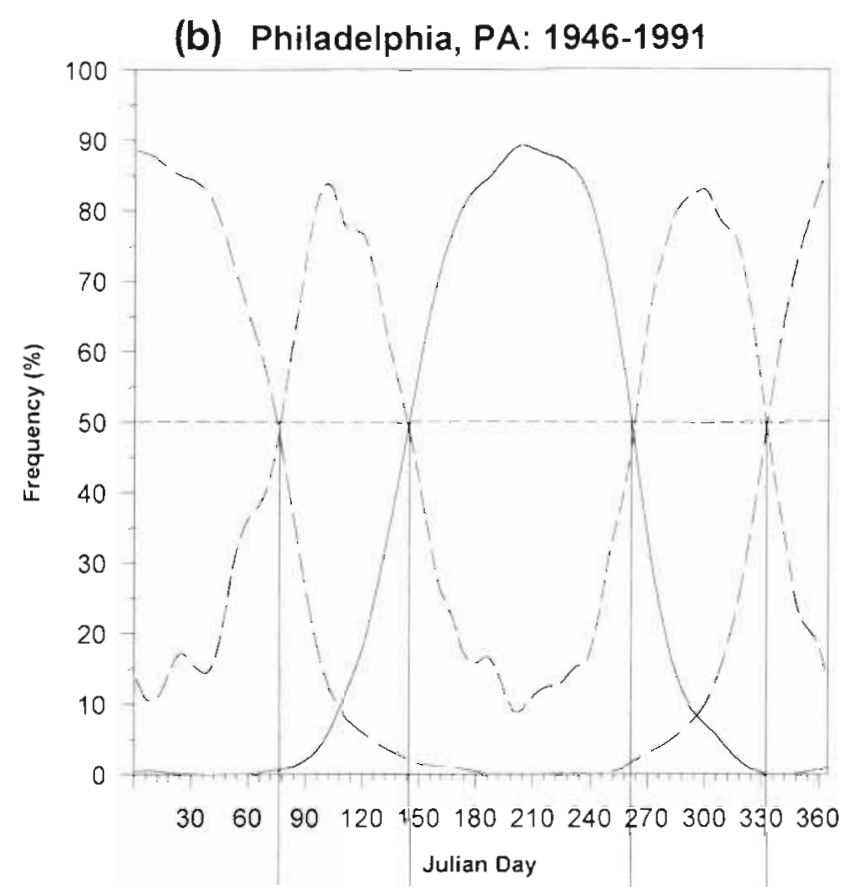

March 17 May 25

September 19 November 29

(d) Miami, FL : 1948-1991

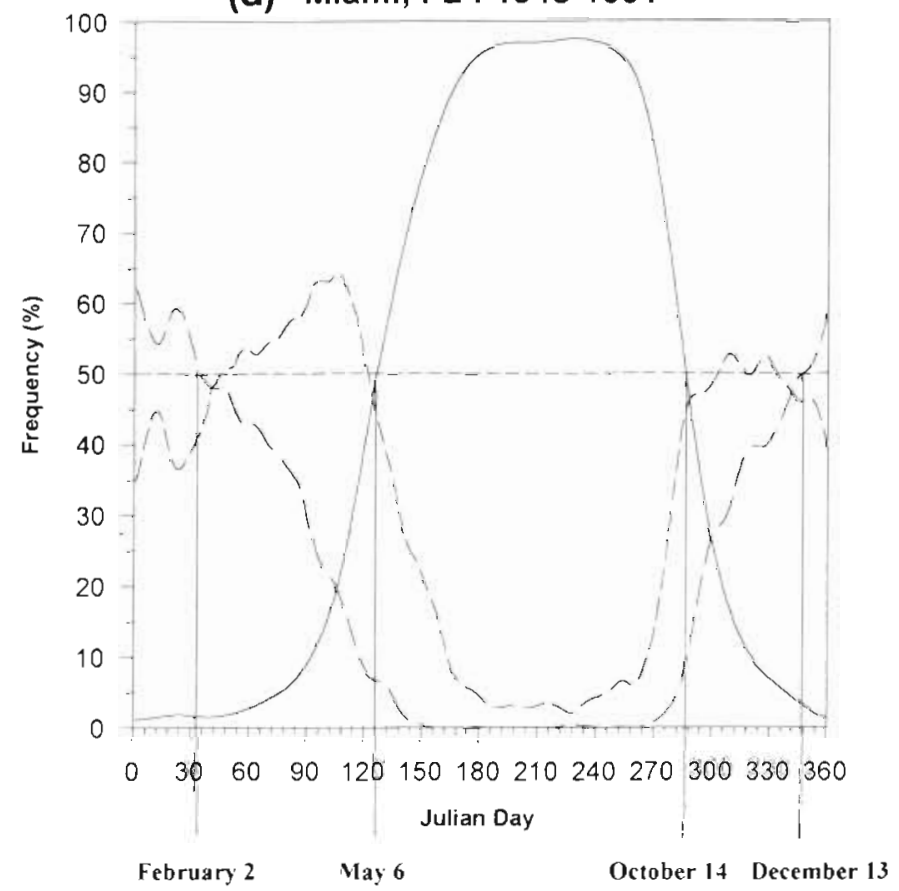

Fig. 2. Distributions of seasonal air mass frequencies in (a) Portland, (b) Philadelphia, (c) Norfolk, (d) Miami. ( $\longrightarrow$ ) Summer, $(-\ldots$ winter, $(--)$ spring and autumn, (----) $50 \%$ frequency

more inland stations, such as Hartford, Richmond, and Columbia, the first day of the summer is always earlier than the adjacent stations closer to the ocean. The local impact of marine influences on the modification of air masses is clearly indicated.
Autumn commences from early September in Maine to mid-October in Florida. Although the change averages $2.2 \mathrm{~d}$ per $100 \mathrm{~km}$, there appears to be little difference between Philadelphia (September 19) and Charleston (September 29). Frequent autumn air mass 


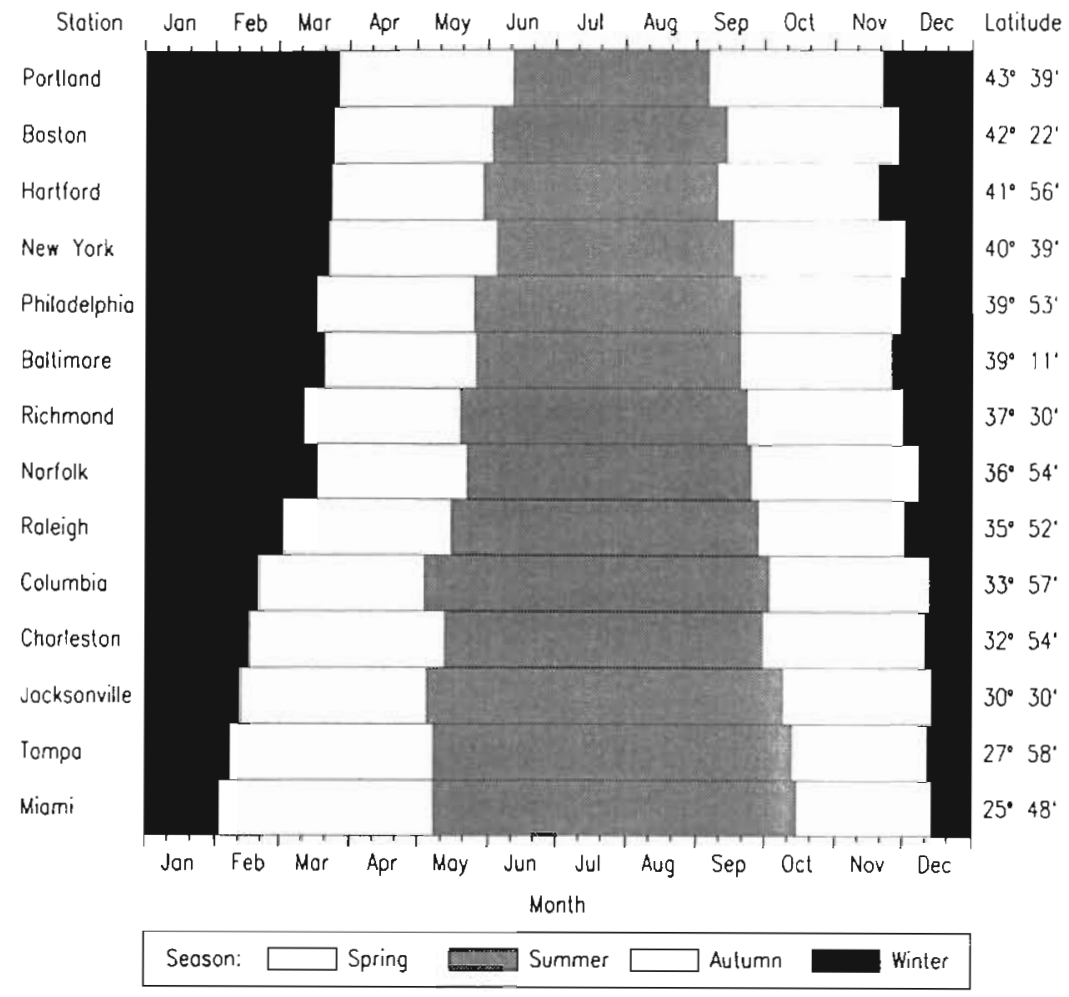

Fig. 3. Climatological seasons over the East Coast
Florida than in Maine. However, at least one other study found a latitudinal gradient even weaker than ours (Pielke et al. 1987). An interesting finding is the importance of distance from the coast. Inland stations generally demonstrated an earlier onset of summer, and, in some cases, winter Occasionally, distance from the coast was a more important determinant of seasonality than latitude.

Some suggestions can be offered regarding temporal and spatial seasonal variation. For example, it appears that the zone of greatest baroclinicity (and associated long-wave features) retreats rapidly north to the latitude of Norfolk during February. Circulation patterns in March from Norfolk northward continue to be decidedly winterlike (Brádka 1966, Whittaker \& Horn 1982, Barnston \& Livezey 1987), thus explaining somewhat the similar date for the beginning of spring from this latitude northward. The role of solar radiation in warming late-winter air masses is not quantitatively understood, but increased solar angle in February at the southern stations may play a role in modifying air masses to appear more springlike. The beginning of summer varies little with latitude from Columbia southward, probably attributed to the barotropic nature of the atmosphere in the southern U.S. from mid-May through the summer season.

There is a need to understand other facets of this seasonality trend. For example, the lack of latitudinal gradient for the onset of winter from Columbia southward is difficult to understand. The systematic increase in the length of the spring season and decrease in the length of fall from Norfolk southward is similarly difficult to explain. However, it seems clear that evaluating season length based on air mass dominance represents one adequate means to determine how seasonality varies across a latitudinal gradient.

\subsection{Robustness of procedure}

To test the robustness of the procedure, $5 \%, 10 \%$, and $20 \%$ of the seed days were randomly deleted from the original sample for each air mass for Philadelphia and Norfolk, respectively. The SSC was rerun based on this new seed day sample to classify air masses, and new frequencies were computed to determine season length. The results proved almost identical to the original seasonal determinations for both cities. In ad-

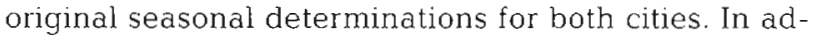

pected a larger gradient across the region, and it is surprising that summer extends only 2 mo longer in
It is difficult to explain some of the temporal and spatial differences in the seasons, and some of the results appear counterintuitive. For example, we ex- 
dition, the monthly mean afternoon temperatures and dew points for each air mass did not change significantly at each location. Thus, the SSC results seem robust, and the observations regarding season length appear to be consistent.

\subsection{Comparisons between studies}

There are several other studies which have attempted to determine length of season using meteorological or phenological factors. Of these, Lamb (1950) and Pielke et al. (1987) used the frequencies of surface synoptic events, such as weather types or air masses, while Bryson \& Lahey (1958) used the annual variations of sea-level pressure, synoptic patterns, and circulation indices to divide the seasons. Most other studies used upper-level atmospheric circulation patterns to define seasons (e.g. Brádka 1966, Kalnicky 1987, Matsumoto 1990).

Although the definition of seasonal divisions are different among these studies, there seems to be some general agreement. For example, our results for sites north of Philadelphia and those found by Brádka (1966) based on the position of the jet stream and the path of surface pressure systems are quite similar. Brádka indicates that spring begins in early March, summer in early June, fall around the first of September, and winter in early November. Our results for north of Philadelphia show seasonal start dates of mid-March, late May to early June, early to midSeptember, and middle to late November respectively. However, in some cases, our results are clearly different from those of previous studies. For example, Pielke et al. (1987) concluded that seasons vary little with latitude along the Gulf and Atlantic coasts of the U.S. In addition, dates for season commencement are quite different; Pielke et al. (1987) indicate that winter does not end until mid-April in New York City (our results show March 22), and fall lasts less than 1 mo (we indicate $2.5 \mathrm{mo}$ ). Results for Miami are closer to ours, but our winter ends about 2 mo earlier.

There is some seasonal correspondence with studies which evaluate the onset of phenological events [Table 3; dates for some of these events were interpolated from U.S. Department of Agriculture (1936) maps, and those constructed by Higbee (1958)], but our latitudinal gradients are generally weaker. Schwartz \& Marotz (1986) computed the mean first leaf emergence dates of the clone lilac, Syringa chinensis, for the period 1961 to 1980 across eastern and central North America. The average date of observed first leaf varies from March 31 in Philadelphia to April 20 in Portland. This represents a stronger temporal gradient than our results for the onset of spring (March 17 in Philadelphia and March 26 in Portland). Strong warm air advection usually occurs about $2 \mathrm{wk}$ prior to first leaf, and these studies strongly suggest that the changes in climatological seasons are related to surface synoptic (air mass) events which control emergence (Schwartz \& Marotz 1988, Schwartz \& Karl 1990); we fully agree (refer to Kalkstein 1991b).

Other phenological events, such as the harvesting of green beans/potatoes, the last killing frost in spring, and the first killing frost in autumn, change systematically with latitude (Table 3 ). In general, the latitudinal gradient of these events is stronger than ours, especially for harvesting dates from Richmond southward. Gradients for harvesting dates from Philadelphia northward are somewhat similar to ours.

Table 3. Average dates of some tree and crop phenological events as well as first days of seasons. NA: not applicable

\begin{tabular}{|c|c|c|c|c|c|c|c|c|c|c|}
\hline \multirow[t]{2}{*}{ City } & \multirow{2}{*}{$\begin{array}{l}\text { First leaf } \\
\text { (Syminga } \\
\text { chinensis) }\end{array}$} & \multicolumn{2}{|c|}{ Harvest beginning ${ }^{b}$} & \multirow{2}{*}{$\begin{array}{l}\text { Last kill- } \\
\text { ing frost } \\
\text { in spring }\end{array}$} & \multirow{2}{*}{$\begin{array}{l}\text { First kill- } \\
\text { ing frost } \\
\text { in fall }\end{array}$} & \multirow{2}{*}{$\begin{array}{c}\text { Natural } \\
\text { vegetation }{ }^{c}\end{array}$} & \multicolumn{4}{|c|}{ First days of seasons ${ }^{d}$} \\
\hline & & $\begin{array}{l}\text { Green } \\
\text { beans }\end{array}$ & Potatoes & & & & Spring & Summer & Autumn & Winter \\
\hline Portland & Apr 20 & Jul 10 & Jul 11 & May 8 & Oct 10 & Birch, beech, & Mar 26 & Jun 11 & $\operatorname{Sep} 5$ & Nov 21 \\
\hline Boston & Apr 17 & Jul 5 & Jul 10 & Apr 29 & Oct 13 & marple, hemlock & Mar 24 & Jun 2 & Sep 13 & Nov 28 \\
\hline Hartford & Apr 15 & Jul 12 & Jul 15 & Apr 25 & Oct 14 & Chestnut, & $\operatorname{Mar} 23$ & May 29 & Sep 9 & Nov 19 \\
\hline New York & Apr 10 & Jul 1 & Jul 5 & Apr 20 & Oct 26 & chestnut, & $\operatorname{Mar} 22$ & Jun 4 & Sep 16 & Dec 1 \\
\hline Philadelphia & Mar 31 & Jun 25 & Jul 1 & Apr 19 & Oct 22 & oak, & Mar 17 & May 25 & Sep 19 & Nov 29 \\
\hline Baltimore & NA & Jun 20 & Jul 1 & Apr 17 & Oct 23 & yellow polar & Mar 20 & May 26 & Sep 19 & Nov 25 \\
\hline Richmond & NA & Jun 1 & Jun 15 & Apr 15 & Oct 26 & & Mar 11 & May 19 & Sep 22 & Nov 30 \\
\hline Norfolk & NA & May 18 & May 28 & Mar 30 & Nov 1 & Oak pine & Mar 17 & May 22 & Sep 24 & $\operatorname{Dec} 7$ \\
\hline Raleigh & NA & Jun 1 & Jun 3 & Apr 5 & Oct 26 & Uak, pine & Mar 2 & May 15 & Sep 27 & Dec 1 \\
\hline Columbia & $\mathrm{NA}$ & May 15 & May 21 & Mar 21 & Nov 13 & & Feb 19 & May 2 & Oct 2 & Dec 12 \\
\hline Charleston & $\mathrm{NA}$ & May 12 & May 5 & Mar 1 & Nov 23 & Longleaf, & Feb 15 & May 11 & Sep 29 & Dec 10 \\
\hline Jacksonville & $\mathrm{NA}$ & Apr 10 & Apr 25 & Feb 28 & Dec 1 & Joblolly, & Feb 11 & May 3 & Oct 8 & $\operatorname{Dec} 13$ \\
\hline Tampa & NA & Mar 15 & $\operatorname{Mar} 25$ & NA & NA & slash pines & Feb 7 & May 6 & Oct 12 & Dec 11 \\
\hline Miami & $N A$ & Mar 10 & Mar 20 & NA & NA & Mangrove & Feb 2 & May 6 & Oct 14 & Dec 13 \\
\hline
\end{tabular}




\section{CONCLUSIONS AND RECOMMENDATIONS}

The objective of this paper was to define the climatological seasons over the East Coast based on air mass frequencies. The evaluation suggested that seasonlength varies systematically with latitude, but in a manner that was sometimes unexpected. Winter occurs from late November to late March in Portland and from mid-December to early February in Miami. Summer is from mid-June to early September in Portland, and from early May to mid-October in Miami.

The first day of spring changes much more rapidly south of Baltimore than north. In addition, the latitudinal gradient for the first day of spring is greater than for the other seasons. Location with relation to the coast is, in some cases, as important as latitude in determining the timing of the seasons. A comparison with other studies and with specific phenological events indicates that synoptic-based seasonality evaluations show a lesser latitudinal gradient than does phenological timing.

One question arising from this study involves the role of maritime influences on seasonal air masses. It appears that air masses are sometimes modified to such an extent along the coast that they are placed into a different season. For example, early spring air masses remain relatively cool in Norfolk (as opposed to Richmond) due to maritime modification, and are subsequently classified as winter air masses. Thus, winter lasts about a week later in Norfolk. In addition, there is a need to analyze more completely some of the physical reasons for the timing of seasonal changes. We have attempted to offer some explanations, and an air mass-based approach such as the one used here does permit additional analysis.

This air mass-based regional delineation of seasons can be used in a variety of environmental analyses. These include:

- climate-biotic interactions. Although plant phenology is closely tied to seasonal changes, factors such as cycles in animal demographics and migrations are also important. The changes in air mass frequency and character associated with seasonal changes can provide an explanation for migratory or reproductive habits of animals.

- climate change studies. Although this study evaluates a period of over $40 \mathrm{yr}$, it is possible that long- or short-term climate variations may have a significant impact on season length. Thus, it is possible to break down the record into shorter increments to determine if any systematic changes in season commencement or length are occurring.

- human health analysis. Certain human conditions, such as asthma, heat-related illnesses, and other factors are seasonally related. For example, great in- creases in asthma attacks occur in early fall (Goldstein 1980), and appear to be triggered by specific synoptic events (rather than just temperature) which are seasonally related (Jamason et al. in press). The onset of frequent incursions of fall air masses may be the trigger to increasing asthma discomfort; knowing the timing of these incursions could assist in the development of an asthma-weather watch/warning system.

- assistance to electric utility companies and other seasonally-based industries. As mentioned previously, most businesses utilize a fixed schedule to determine seasonal transition. This study could provide further guidance into the nature of seasonal changes.

- regional climate classification. It is possible that a climate classification scheme can be formulated based upon season length and character as expressed by air masses. Schemes based on changes in singular meteorological elements, such as air temperature, are decidedly inferior to those which evaluate the frequency and character of synoptic situations. Single elements are incapable of describing the more complicated atmospheric factors which are associated with the changing seasons. The modification of air masses, and their changing frequencies, are much more accurate delineators of seasonal changes.

Acknowledgements. We wish to express our appreciation to Dr Scott Greene, Mr David Barthel, and Mr Michael Nichols for providing the software of the spatial synoptic classification. We also thank Drs John Mather and Daniel Leathers Department of Geography, University of Delaware, and Prof. Guanri Tan, Department of Atmospheric Sciences, Zhongshan University, China, for their thoughtful suggestions.

\section{LITERATURE CITED}

Barnston AG, Livezey RE (1987) Classification, seasonality and persistence of low-frequency atmospheric circulation patterns. Mon Weather Rev 115:1083-1126

Brádka J (1966) Climatological seasons on the Northern Hemisphere. Geofys Sb 262:597-648

Bryson RA, Lahey JF (1958) The march of seasons. Air Force, Cambridge Research Center, Final Report, No. 19-(604)992. University of Wisconsin, Madison

Cheng S (1991) Synoptic climatological categorization and human mortality in Shanghai, China. Proc Middle State Div AAG 24:5-11

Cheng $S$ (1996) A definition of climatological seasons and an analysis of air mass modification over the East Coast using a year-round spatial synoptic classification. PhD dissertation, University of Delaware, Newark

Cheng S, Ye H, Kalkstein LS (1992) An evaluation of pollution concentrations in Philadelphia using an automated synoptic approach. Middle States Geographer 25:45-51

Goldstein IF (1980) Weather patterns and asthma epidemics 
in New York City and New Orleans, USA. Int J Biometeorol 24(4):329-339

Gordon AH (1953) Seasonal changes in the mean pressure distribution over the world and some inferences about the general circulation. Bull Am Meteorol Soc 34:357-36?

Green MC (1993) Use of temporal principal components analysis to determine seasonal periods. J Appl Meteorol 32:986-995

Greene JS (1995) Precipitation variability and analysis of satellite-derived rainfall using a spatial synoptic classification. PhD dissertation, University of Delaware, Newark

Higbee E (1958) American agriculture: geography, resources, conservation. John Wiley \& Sons, New York

Jamason PF, Kalkstein LS, Gergen P (in press) A synoptic evaluation of asthma hospital admission in New York City. Am Rev Resp Dis Crit Care Med

Kalkstein LS (1991a) A new approach to evaluate the impact of climate on human mortality. Envir Health Perspectives 96:145-150

Kalkstein LS (1991b) Bioclimatological research: the issue of climatic sensitivity. Phys Geogr 12(3):274-286

Kalkstein LS, Barthel CD, Greene JS, Nichols MC (1996) A new spatial synoptic classification: application to air mass analysis. Int J Climatol 16(8):983-1004

Kalkstein LS, Corrigan P (1986) A synoptic climatological approach for environmental analysis: assessment of sulfur dioxide concentrations. Annals AAG 76:381-395

Kalnicky RA (1987) Seasons, singularities, and climatic changes over the midlatitudes of the Northern Hemisphere during 1899-1969. J Clim Appl Meteorol 26:1496-1510

Lamb HH (1950) Types and spells of weather around the year in the British Isles: annual trends, seasonal structure of the year, singularities. Q J R Meteorol Soc 76:393-438

Lie KN, Wu HS (1956) A preliminary study of the determina-

Editor: B. Yarnal, University Park, Pennsylvanıa, USA tion of national synoptic summer season over Asiatic national synoptic region and the prevailing weather process in this season. Acta Meteorol Sin 27:219

Matsumolo J (1990) The seasonal changes of wind fields in the global tropics. Geogr Rev Jap 63B(2):156-178

McCabe GJ Jr (1985) Development of objective temporal and spatial synoptic indices. MSc thesis, University of Delaware, Newark

McMichael AJ, Haines A. Slooff R, Kovats S (1996) Climate change and human health. WHO/WMO/UNEP, Geneva

Pielke RA, Garstang M, Lindsey C, Gusdorf J (1987) Use of a synoptic classification scheme to define seasons. Theor Appl Clim 38:57-68

Schwartz MD, Karl TR (1990) Spring phenology: nature's experiment to detect the effect of 'Green-up' on surface maximum temperatures. Mon Weather Rev 118:883-890

Schwartz MD, Marotz GA (1986) An approach to examining regional atmosphere-plant interactions with phenological data. J Biogeogr 13:551-560

Schwartz MD, Marotz GA (1988) Synoptic events and spring phenology. Phys Geogr 9:151-161

U.S. Department of Agriculture (1936) Atlas of American agriculture-physical basis including land relief, climate, soils and natural vegetation. United States Government Printing Office, Washington, DC

Whittaker LH, Horn LE (1982) Geographical and seasonal distribution of North American cyclogenesis, 1958-1977. Mon Weather Rev 109:2312-2322

Yeh TC, Chu PC (1958) Some fundamental problems of the general circulation of the atmosphere. Institute of Geophysics and Meteorology, Academy Seneca Taipei, Taiwan

Zhang BK (1934) The distribution of four seasons in China. Acta Geogr Sinica 1(1):19-56 (in Chinese)

Manuscript first received: March 27, 1996

Revised version accepted: January 31, 1997 